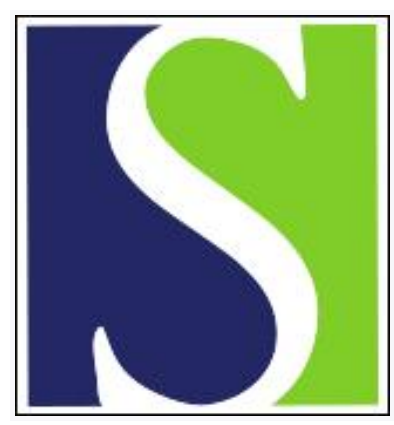

Scand J Work Environ Health 1995;21(4):272-276

https://doi.org/10.5271/sjweh.37

Issue date: Aug 1995

Male-mediated risk of spontaneous abortion with reference to stainless steel welding

by Hjollund NHI, Bonde JPE, Hansen KS

Key terms: hexavalent chromium; metal worker; mutagenic effect; paternal exposure; pregnancy outcome; register linkage

This article in PubMed: www.ncbi.nlm.nih.gov/pubmed/8553001

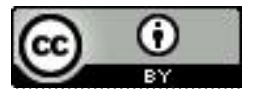




\title{
Male-mediated risk of spontaneous abortion with reference to stainless steel welding
}

\author{
by Niels HI Hjollund, MD, Jens PE Bonde, MD, ${ }^{1}$ Klaus S Hansen, $M D^{2}$
}

\begin{abstract}
Hjollund NHI, Bonde JPE, Hansen KS. Male-mediated risk of spontaneous abortion with reference to stainless
\end{abstract} steel welding. Scand J Work Environ Health 1995;21:272-6.

\begin{abstract}
Objectives It was hypothesized that the welding of stainless steel involves a risk of male-mediated developmental toxicity because of exposure to mutagenic substances, including hexavalent chromium. The purpose of the present study was to corroborate or refute earlier findings that spouses of stainless steel welders have an increased risk of spontaneous abortion.

Methods The occurrence of spontaneous abortion among 2520 pregnancies of spouses of 1715 married metal workers from 1977 through 1987 was examined. Occupational histories were collected with a postal questionnaire in a previous study. Information on children born live, spontaneous abortion, and induced abortion was obtained from national medical registers.

Results The proportion of spontaneous abortions was not increased for pregnancies at risk from stainless steel welding when compared with pregnancies not at risk (odds ratio $0.78,95 \%$ confidence interval $0.55-1.1$ ). The risk estimate was robust to adjustment for potential confounding effects of maternal age and parity and male smoking and alcohol consumption.

Conclusions This study does not corroborate earlier findings that spouses of stainless steel welders have increased risk of spontaneous abortion. A reanalysis indicated that earlier findings were probably biased because the job exposure of male metal workers is apparently modified by the outcome of their partners' first pregnancy.
\end{abstract}

Key terms hexavalent chromium, metal workers, mutagenic effects, paternal exposure, pregnancy outcome, register linkage.

Male-mediated developmental toxicity has achieved increased attention during recent years $(1,2)$. The welding of stainless steel is associated with the pulmonary uptake of hexavalent chromium, which is known to have mutagenic effects in both somatic cells and germ cells (3). Several studies have found reduced fecundity in terms of semen quality and fertility among welders, but most effects have been attributable to the welding of mild steel - not to the welding of stainless steel (4).

A nationwide cohort study of pregnancy outcome among metal workers found an increased risk of spontaneous abortion for spouses of stainless steel welders [odds ratio (OR) 2.0, 95\% confidence interval (95\% CI) $1.1-3.5]$, but not for those of mild steel welders (OR $1.1,95 \%$ CI $0.5-2.4$ ) (5). These results were based on an analysis of abortions reported to the midwife and subsequently recorded in the Medical Birth Register. This design did not allow for the exact timing of paternal exposure relative to the outcome since the date of the abortion was unknown. The purpose of the present study was to corroborate or refute the earlier findings with a design using in-patient register information on spontaneous abortion and taking paternal exposure at the time of conception into account.

\section{Subjects and methods}

The source population was a cohort of 10059 Danish metal workers employed in steel manufacturing companies for a minimum of one year within the period 1964 through 1984. The cohort was created from records in the Danish Labor Pension Fund for men who were at any time employed as production workers. This cohort was originally created for a study of occupational cancer risk. During the autumn of 1986 the cohort members were sent a questionnaire. Completed questionnaires were re- 
ceived from $85 \%$ of the cohort members. Information on the welding of mild steel and stainless steel was obtained from a separate series of questions. For each type of welding the workers were asked to record the first and last years worked and the number of years that the particular type of welding had been performed in each of the following three periods: $1960-1969,1970-1979$, and 1980-1986. A detailed description of the cohort has been given elsewhere (5).

Spouses of the metal workers were identified from records in the Danish Central Population Register, which also provided dates on marriage and divorce. In the period 1 January 1977 through 31 December 1987, 6739 metal workers were married to 7153 women for an average of 9.2 years. Information on children born live was collected from the spouses' records in the same register.

Data on hospital discharges with a diagnosis of spontaneous, induced or unspecified abortion, ectopic pregnancy or hydatidiform mole (codes 631, 640-645 of the International Classification of Diseases, eighth revision) were collected by record linkage to the Danish In-patient Hospital Register. Discharge from the hospital more than once within a period of $60 \mathrm{~d}$ appeared in 131 of 1358 records and was considered to represent rehospitalization for the same disorder. In such cases only the first discharge was included unless a subsequent discharge had a more specific diagnosis ( 5 cases).

The time of conception was considered to be 38 weeks before delivery in the case of birth and nine weeks before hospital discharge in the case of abortion. The study base comprised 2520 pregnancies conceived during marriage according to the aforementioned criteria from 1 January 1977 through 31 December 1987 (figure 1).

\section{Analysis and statistical methods}

The unit of observation was a pregnancy defined by either a birth of a child born live, a spontaneous abortion, an induced or unspecified abortion, or an ectopic pregnancy. A pregnancy was designated at risk from welding exposure in the $90 \mathrm{~d}$ preceding conception so that the duration of spermatogenesis would be taken into account. In addition each pregnancy was identified with the number of years the man worked with welding prior to conception, the age of the mother, the parity of the mother $(0,1, \geq 2)$, male smoking (yes, no) and consumption of alcoholic beverages (high, low) of the father. The characteristics of the pregnancies are given in table 1 for the exposure categories.

The occurrence of spontaneous abortion $\left[\mathrm{N}_{\text {spontaneous }}\right.$ abortions $/\left(\mathrm{N}_{\text {births }}+\mathrm{N}_{\text {spontancous abortions }}+\mathrm{N}_{\text {induced abortions }}+\mathrm{N}_{\text {other preg- }}\right.$ nancies)] was analyzed by logistic regression on male welding exposure and the aforementioned covariates (6).

\section{Results}

The occurrence of spontaneous abortion was not increased for pregnancies at risk from either stainless steel or mild steel welding exposure (table 2). Adjustment for maternal age and parity and male smoking and alcohol consumption resulted in essentially the same risk estimates. In a separate analysis we compared the proportion of spontaneous abortions among spouses of stainless steel welders with the proportion of spontaneous abortion among spouses of mild steel welders and found no dif-
Figure 1. Collection of information on pregnancy outcome 1977 through 1987 for spouses of a cohort of metalworkers. (a) 43 ectopic pregnancies, 15 unspecified abortions, and 2 hydatidiform moles)

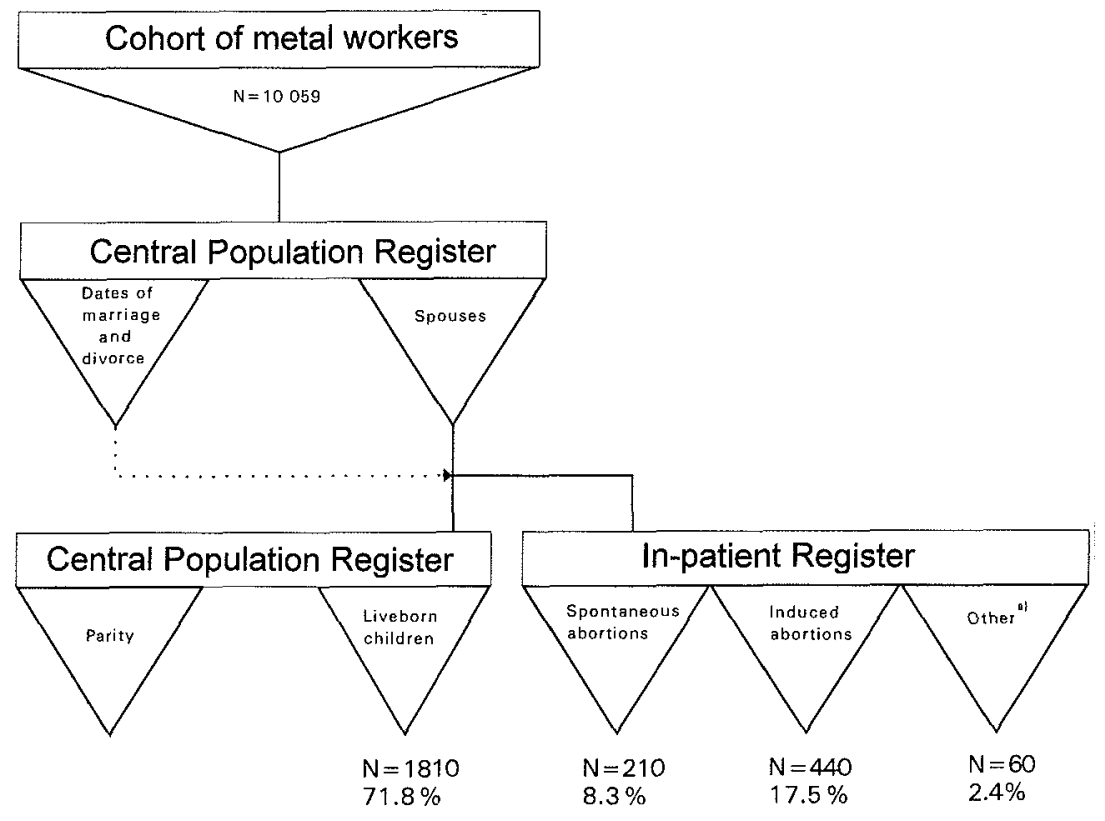

Scand J Work Environ Health 1995, vol 21, no 4 
Table 1. Characteristics of pregnancies according to exposure category.

\begin{tabular}{|c|c|c|c|c|c|c|c|c|c|}
\hline & \multirow{2}{*}{$\begin{array}{l}\text { Pregnancies } \\
(\mathrm{N})\end{array}$} & \multicolumn{2}{|c|}{ Age of spouse } & \multicolumn{2}{|c|}{ Year of birth } & \multirow{2}{*}{$\begin{array}{l}\text { Paritya } \\
\text { (mean) }\end{array}$} & \multirow{2}{*}{$\begin{array}{l}\text { Urban } \\
\text { residenceb } \\
(\%)\end{array}$} & \multirow{2}{*}{$\begin{array}{c}\text { Smoking } \\
(\%)\end{array}$} & \multirow{2}{*}{$\begin{array}{c}\text { High alcohol } \\
\text { consumption } \\
(\%)\end{array}$} \\
\hline & & Mean & SD & Mean & SD & & & & \\
\hline Stainless steel welding & 865 & 28.2 & 5.0 & 49.6 & 5.9 & 1.21 & 46.7 & 63.1 & 18.5 \\
\hline Mild steel welding & 618 & 27.8 & 4.7 & 49.6 & 5.5 & 1.15 & 39.3 & 60.7 & 18.6 \\
\hline No welding & 1037 & 28.8 & 5.3 & 48.6 & 6.3 & 1.35 & 45.2 & 58.6 & 13.5 \\
\hline
\end{tabular}

a Parity $\geq 3$ has been computed as parity 3 .

Information on residence available for births only.

Table 2. Unadjusted odds ratios for spontaneous and induced abortion in 1977 through 1987 according to paternal exposure to welding. (OR $=$ odds ratio, $95 \% \mathrm{Cl}=95 \%$ confidence interval)

\begin{tabular}{|c|c|c|c|c|c|c|c|c|c|c|}
\hline & \multicolumn{4}{|c|}{$\begin{array}{l}\text { Pregnancies at risk from } \\
\text { stainless steel welding }(N=865)\end{array}$} & \multicolumn{4}{|c|}{$\begin{array}{l}\text { Pregnancies at risk from } \\
\text { mild steel welding }(N=618)\end{array}$} & \multicolumn{2}{|c|}{$\begin{array}{l}\text { Pregnancies not } \\
\text { at risk }(N=1037)\end{array}$} \\
\hline & N & $\%$ & OR & $95 \% \mathrm{Cl}$ & N & $\%$ & OR & $95 \% \mathrm{Cl}$ & $N$ & $\%$ \\
\hline \multicolumn{11}{|c|}{ Spontaneous abortion } \\
\hline $\begin{array}{l}\text { Parity } 0 \\
\text { Parity } 1 \\
\text { Parity } \geq 2 \\
\text { Overall }\end{array}$ & $\begin{array}{l}18 \\
22 \\
22 \\
62\end{array}$ & $\begin{array}{l}9.4 \\
5.6 \\
7.8 \\
7.2\end{array}$ & $\begin{array}{r}0.61 \\
0.63 \\
1.1 \\
0.78\end{array}$ & $\begin{array}{l}0.32-1.1 \\
0.37-1.1 \\
0.63-2.0 \\
0.55-1.1\end{array}$ & $\begin{array}{l}13 \\
25 \\
16 \\
54\end{array}$ & $\begin{array}{l}9.4 \\
8.5 \\
8.7 \\
8.7\end{array}$ & $\begin{array}{r}0.61 \\
0.98 \\
1.3 \\
0.96\end{array}$ & $\begin{array}{l}0.30-1.2 \\
0.58-1.7 \\
0.66-2.4 \\
0.68-1.4\end{array}$ & $\begin{array}{l}27 \\
38 \\
29 \\
94\end{array}$ & $\begin{array}{r}14.5 \\
8.7 \\
7.0 \\
9.1\end{array}$ \\
\hline \multicolumn{11}{|c|}{ Induced abortion } \\
\hline $\begin{array}{l}\text { Parity } 0 \\
\text { Parity } 1 \\
\text { Parity } \geq 2 \\
\text { Overall }\end{array}$ & $\begin{array}{r}5 \\
26 \\
122 \\
153\end{array}$ & $\begin{array}{r}2.6 \\
6.7 \\
43.1 \\
17.7\end{array}$ & $\begin{array}{r}0.68 \\
1.0 \\
1.2 \\
0.93\end{array}$ & $\begin{array}{l}0.21-2.2 \\
0.60-1.8 \\
0.88-1.6 \\
0.73-1.2\end{array}$ & $\begin{array}{r}7 \\
18 \\
67 \\
92\end{array}$ & $\begin{array}{r}5.0 \\
6.1 \\
36.2 \\
14.9\end{array}$ & $\begin{array}{l}1.4 \\
0.96 \\
0.90 \\
0.76\end{array}$ & $\begin{array}{l}0.47-4.0 \\
0.52-1.8 \\
0.63-1.3 \\
0.58-0.99\end{array}$ & $\begin{array}{r}7 \\
28 \\
160 \\
195\end{array}$ & $\begin{array}{r}3.7 \\
6.4 \\
38.8 \\
18.8\end{array}$ \\
\hline
\end{tabular}

a Irrespective of concurrent mild steel welding.

- Not at risk for stainless steel welding.

ference in the risk estimate (OR 0.81, 95\% CI 0.6-1.2). Even the use of the manual metal-arc welding method on stainless steel, which leads to higher exposure to welding fumes, was not related to an increased risk (OR 0.78, 95\% CI 0.5-1.1). Similarly, we found no indication that the number of hours of welding per day or the number of previous years of welding was related to the occurrence of spontaneous abortion.

\section{Discussion}

The overall frequency of hospital-treated spontaneous abortion was $8.5 \%$ in our sample, a value within the range of the national average of $9.3 \%$ (7). The proportions of spontaneous abortion were controlled for potential confounding effects of the most important known extraneous determinants (female age and parity). When comparing proportions of spontaneous abortion among wives of stainless steel welders with those of wives of mild steel welders and nonwelding metal workers, we found it unlikely that yet unknown risk factors would confound the results. The frequency of induced abortion was rather high in all of the exposure groups (table 2). When the occurrence of spontaneous abortion was com- pared between groups, the induced abortions were included in the total number of pregnancies. This approach reduced the distorting effect of induced abortion on risk estimates of spontaneous abortion (8).

The earlier finding indicating increased risk of spontaneous abortion among spouses of stainless steel welders (5) was not corroborated by this study. The reason for this discrepancy is probably differences in the sources of information on abortion.

First, the reliability of the data in the two registers, the Medical Birth Register and the In-patient Hospital Register, might differ. A recent evaluation of diagnoses classified according to the International Classification of Diseases, eighth revision, in the In-patient Hospital Register has shown concordance with hospital records in $90 \%$ of the discharges when the comparison was done according to the first three digits of the code (9). Data on previous pregnancies in the Medical Birth Register were reported by the woman giving birth and recorded by the midwife. A Danish study dealing with self-reported information on abortion has shown that $17 \%$ of women report fewer spontaneous abortions when asked again after 3.5 years, and the capability to recall differs between two groups of workers (10). Another study comparing self-reported data on abortions with data from the In-patient Hospital Register found that $13 \%$ of the spon- 
taneous abortions recorded in the hospital register were not reported in a self-administered questionnaire (11). The corresponding figure was $25 \%$ for induced abortions. Using the data presented in this paper, we have examined whether increases in self-reported abortions in the records of the Medical Birth Register for the same woman from successive births was in agreement with the records of abortions in the in-patient register in the interval between the births. For 580 women, 82 cases with a self-reported or hospital-recorded spontaneous abortion were identified. In 35 cases there was agreement, in 14 cases a spontaneous abortion was reported to the birth register but not recorded in the hospital register, in 7 cases a spontaneous abortion was recorded in the hospital register but not in the birth register, and in 18 cases a spontaneous abortion reported to the birth register at one birth was not reported at the time of the next birth. It appears that the reliability of the information on earlier pregnancy outcome in the Medical Birth Register can be questioned. Nevertheless, the misclassification is fairly unlikely to be related to exposure and can hardly explain the discrepancy between this study and the earlier one.

Second, the Medical Birth Register contains no information on the dates of previous abortions, only the number of abortions. For this reason it is not possible to assess properly the exposure status at the time of conception when the records from the Medical Birth Register are used. In the earlier study a previous pregnancy was designated at risk from paternal welding exposure if the subsequent birth in the Medical Birth Register (the index birth) was categorized as at risk. The analysis only included births with one preceding pregnancy, and accord- ingly women who reported a previous abortion were childless until the date of the index birth. If the outcome of the pregnancy preceding the index birth modified the paternal work exposure, bias might have been introduced. Surprisingly, this appears indeed to be the case. For couples without children the mail spouse was more likely to be welding stainless steel than the male spouse of couples with one or more children, and this relation was independent of paternal age and birth year (figure 2). On the contrary, the welding of mild steel appears not to have been dependent on whether the couple had children or not (figure 3). When the exposure status of the first pregnancy was assigned according to the exposure status of the index birth, the risk of spontaneous abortion following exposure to stainless steel welding, but not mild steel welding, was biased in a positive direction. Accordingly, the apparent increased risk of spontaneous abortion among stainless steel welders in the earlier study was probably noncausal. The reason why metal workers with no children seem more likely to perform stainless steel welding is not clear. It is possible that metal workers without children are less reluctant to work abroad or at places distant from their homes, and these factors could be associated with stainless steel welding.

Finally, our study was based on abortions recorded in a hospital register, while the earlier study was based on self-reported data, which probably included more early abortions. Loss that is undetected early in pregnancy by the woman and the health care system appears to be a frequent phenomenon (12). If an environmental factor is selectively causing damage to conceptuses at an early stage and thus is resulting in a high frequency of early
Figure 2. Proportions of metal workers performing stainless steel (SS) welding in 1973 through 1986 according to family size.

\section{Proportion of metal workers}

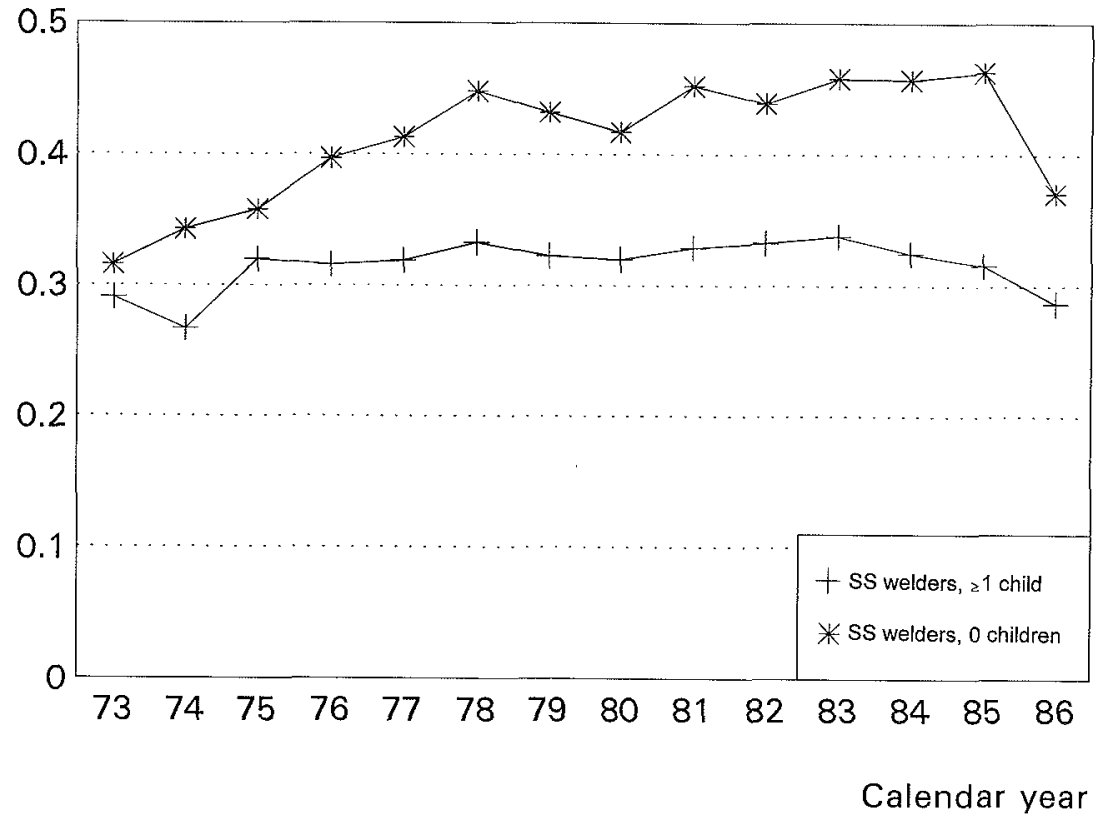


Proportion of metal workers

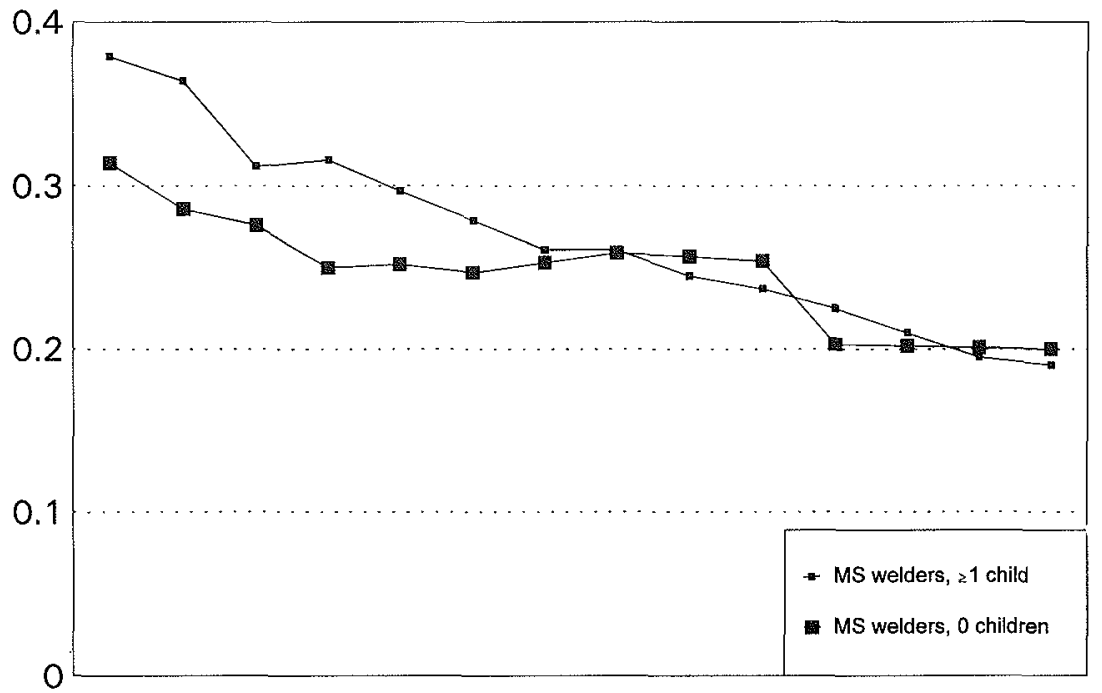

$\begin{array}{llllllllllllll}73 & 74 & 75 & 76 & 77 & 78 & 79 & 80 & 81 & 82 & 83 & 84 & 85 & 86\end{array}$
Figure 3. Proportions of metal workers performing mild steel (MS) welding in 1973 through 1986 according to family size. pregnancy loss, the proportion of late abortions can appear normal or even low in spite of a high total risk of spontaneous abortion (13). Early embryonal loss shows up as an increased time to pregnancy or infertility. Several studies link paternal welding exposure with reduced male fecundity and couple fertility, but the effects have rather consistently been attributable to the welding of mild steel (4). Nevertheless the observed and apparently "normal" frequency of clinically recognized abortions in our study does not rule out the possibility that stainless steel welding selectively causes embryonal loss at the early stages of development. Still the majority of early miscarriages remained undetected in the earlier study, too, and the fact that self-reported abortions in pregnancies at risk from exposure were traced in the hospital records with a higher frequency $(85 \%)$ than abortions in pregnancies not at risk $(77 \%)$ indicated that the difference of the risk estimates was probably not explained by an excess of early abortions among the stainless steel welders.

In conclusion, we found no evidence that paternal exposure to mutagenic substances in stainless steel welding causes increased risk of spontaneous abortion among spouses. The earlier finding might be spurious because of a lack of information on the date of abortion and therefore might have led to a biased assignment to risk categories.

\section{Acknowledgements}

This work was supported by a grant from Helsefondet, Denmark.

\section{References}

1. Colie CF. Male mediated teratogenesis. Reprod Toxicol 1993; 7:3-9.

2. Olshan AF, Faustman EM. Male-mediated developmental toxicity. Reprod Toxicol 1993;7:191-202.

3. Knudsen I. Mammalian spot test and its use for testing of potential carcinogenicity of welding fume particles and hexavalent chromium. Acta Pharmacol Tocicol 1980;47:66-70.

4. Bonde, JPE. The risk of male subfecundity attributable to welding of metals. Int J Androl 1993;16 suppl 1:1-29.

5. Bonde JPE, Olsen J, Hansen KS. Adverse pregnancy outcome and childhood malignancy with reference to paternal welding exposure. Scand J Work Environ Health 1992;18:169—77.

6. SAS Institute Inc. SAS/STAT, users' guide, release 6.03 Edition. Cary, NC: SAS institute Inc, 1988.

7. Andreasen EE. Births, abortions and extrauterine pregnancies in the community of Funen during 1974-1986. Ugeskr Laeger 1989;151:384-7.

8. Olsen J. Calculating risk ratios for spontaneous abortions: the problem of induced abortions. Int J Epidemiol 1984;13:34750.

9. National Health Service. Evaluering af Landspatient - registeret 1990 [Evaluation of the In-Patient Hospital Registry 1990]. Copenhagen: National Health Service, 1993. Hospital Statistics II:57:1993.

10. Schaumburg I, Olsen J. Risk of spontaneous abortion among Danish pharmacy assistants. Scand J Work Environ Health 1990;16:169-74.

11. Heidam LZ, Olsen J. Self-reported data on spontaneous abortions compared with data obtained by computer linkage with the hospital registry. Scand J Soc Med 1985;13:159_-163.

12. Wilcox AJ, Weinberg CR, O'Conner JF, Baird DD, Schlatterer JP, Canfield RE, et al. Incidence of early loss of pregnancy. N Engl J Med 1988;319:189—94.

13. Källen B. Epidemiology of human reproduction. Boca Raton, FL: CRC Press Inc, 1988.

Received for publication: 13 June 1994 